\title{
DIFFERENT LINEAR POWER FLOW MODELS FOR RADIAL POWER DISTRIBUTION GRIDS: A COMPARISON
}

Pham Nang Van*, Do Quang Duy

Hanoi University of Science and Technology

\begin{tabular}{|c|c|}
\hline & BSTF \\
\hline Rece & \multirow{10}{*}{$\begin{array}{l}\text { In this paper, diverse power flow methodologies for distribution } \\
\text { power networks are reviewed, including Power Summation Method, } \\
\text { Simplified DistFlow, Modified DistFlow and Linearized Power Flow } \\
\text { for Distribution. Among these four models, the power flow equations } \\
\text { of the last three models are linear. The solutions attained from these } \\
\text { three formulas usually have errors compared to Power Summation } \\
\text { Method that solves non-linear power flow equations iteratively. The } \\
\text { voltage magnitudes and branch power flow using different power } \\
\text { flow expressions are determined on a six-bus distribution system. The } \\
\text { calculated results show that the error of the Modified DistFlow } \\
\text { method is much lower than other models. Additionally, the authors } \\
\text { have verified that mathematical expressions for approaches of } \\
\text { Simplified DistFlow and Linearized Power Flow for Distribution are } \\
\text { identical. }\end{array}$} \\
\hline Revised: & \\
\hline & \\
\hline & \\
\hline E & \\
\hline Distri & \\
\hline Power Summatio & \\
\hline & \\
\hline Modified DistFlo & \\
\hline 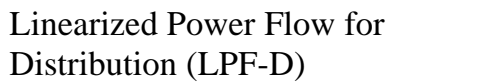 & \\
\hline
\end{tabular}

\section{SO SÁNH CÁC MÔ HÌNH TRÀO LƯU CÔNG SUÂT TUYẾN TÍNH CHO LƯỚI ĐIỆN PHÂN PHỐI HİNH TIA}

Phạm Năng Văn*, Đỗ Quang Duy

Truờng Đại học Bách khoa Hà Nội

\begin{tabular}{|c|c|}
\hline THÔNG TIN BÀI BÁO & TÓM TẮT \\
\hline ii: $16 / 6 / 2021$ & \multirow{10}{*}{$\begin{array}{l}\text { Trong bài báo này, các phương pháp tính trào lưu công suất lưới điện } \\
\text { phân phối được tóm tắt và so sánh. Các phương pháp được xem xét } \\
\text { bao gồm cộng công suất, trào lưu công suất đơn giản hóa, trào lưu } \\
\text { công suất cải biên và trào lưu công suất tuyến tính hóa. Trong đó, } \\
\text { phương pháp cộng công suất có dạng phi tuyến và các phương pháp } \\
\text { trào lưu công suất còn lại có dạng tuyến tính. Kết quả tính toán sử } \\
\text { dụng các mô hình tuyến tính có sai số nhất định so với mô hình phi } \\
\text { tuyến. Các phương pháp tính trào lưu công suất lưới phân phối được } \\
\text { áp dụng cho lưới điện phân phối } 6 \text { nút để tính toán mô-đun điện áp } \\
\text { nút và dòng công suất trên các nhánh. Các kết quả tính toán cho thấy } \\
\text { mô hình trào lưu công suất cải biên có sai số nhỏ nhất so với các mô } \\
\text { hình tuyến tính khác. Ngoài ra, các tác giả cũng chứng minh được } \\
\text { rằng các công thức toán học của mô hình trào lưu công suất đơn giản } \\
\text { hóa và trào lưu công suất tuyến tính hóa hoàn toàn giông nhau. }\end{array}$} \\
\hline Ngày hoàn thiện: 12/8/2021 & \\
\hline Ngày đăng: 12/8/2021 & \\
\hline & \\
\hline TƯ' KHÓA & \\
\hline Lưới điện phân phối & \\
\hline ng suất (PSM) & \\
\hline $\begin{array}{l}\text { Trào lưu công suất đơn giản hóa } \\
\text { (SD) }\end{array}$ & \\
\hline & \\
\hline & \\
\hline
\end{tabular}

DOI: https://doi.org/10.34238/tnu-jst.4665

\footnotetext{
* Corresponding author. Email: van.phamnang@hust.edu.vn
} 


\section{Introduction}

The power flow analysis is a crucial tool in designing, planning and operating power distribution systems. The increasingly expanded grid-scale and penetrated renewables result in the urgent need for controlling and optimizing more effectively [1]. However, due to the nonlinear standard power flow (PF) model, iterative techniques such as Newton-Raphson, Power Summation and Current Summation [2], [3] have been used to find the solution. In addition, optimization problems integrating the standard power flow model such as network reconfiguration [4] and economic dispatch [5] become non-convex and challenging to solve. Researchers have put forward various methodologies to overcome these drawbacks, classifying them into two groups: linearization of the power flow expressions and convex relaxation of power flow equations [4]. However, the disadvantages of both these groups are that the solutions attained are usually different from the global solutions of the initial model.

Among the linearized power flow models, the direct current power flow (DCPF) is the most widely employed by independent system operators in the electricity industry [6]. Nevertheless, DCPF is suitable for the power flow analysis of transmission grids to determine phase angle and active power flow. As a result, developing a linear model applied to distribution grids directly is imperative.

The widely used linear model in power flow analysis for distribution systems is Simplified DistFlow (SD) [3], [7], which assumes that power losses of power networks are neglected, and the voltage magnitudes are approximately equal to 1 to derive voltage equations. The second linear expression is proposed in [8] and [9], namely Linearized Power Flow for Distribution (LPF-D). This second model is based on the bus injection approach and does not consider network losses when deriving the power flow formulas. A novel linear model is recently suggested in [5] and [10], called Modified DistFlow (MD). This model considers P/U and Q/U as state variables and does not neglect directly grid loss terms.

This paper aims to compare a variety of linear techniques to compute steady-state power distribution systems. This research has made significant contributions as follows:

- Review recently developed models of linear power flow for distribution systems;

- Rigorously present a step-by-step procedure proposed in [5] to calculate power flow using a six-bus distribution system;

- Analytically and numerically confirm that the model described in [8] and [9] is the same as the Simplified DistFlow form in [3] and [7];

- Compare the errors of voltage magnitudes and branch power flows from three kinds of linear power flow approaches.

The paper is structured into four sections. Section 2 presents the diverse models of power flow analysis in distribution power networks, including Distribution Power Flow (DistFlow) based on Power Summation Method (PSM), Modified DistFlow (MD), Simplified DistFlow (SD) and Linearized Power Flow for Distribution (LPF-D). Numerical results and discussions using the six-bus distribution system are given in Section 3, and the conclusions are inferred in Section 4.

\section{Methodology}

\subsection{Distribution Power Flow based on Power Summation Method (PSM)}

The Power Summation Method is the Alternating Current Power Flow (ACPF) model. The algorithm for calculating voltages and branch power flows using the Power Summation Method consists of 5 steps [2].

Step 1: Set all voltages to 1 p.u. (flat start). Set iteration account $r=1$.

Step 2: For the set of voltages estimated, compute the net power drawn from each bus:

$$
\dot{S}_{i}^{(r)}=\dot{S}_{i}^{\mathrm{sp}}+y_{\mathrm{si}}^{*}\left(U_{i}^{(r)}\right)^{2} \quad i=N, N-1, \ldots, 2
$$


where $\dot{S}_{i}^{\mathrm{sp}}$ is the complex power absorbed by the demand at bus $i ; y_{\mathrm{si}}$ is the shunt admittance linked to bus $i$, and $N$ is the total buses of power systems.

Step 3 (Backward sweep):

Sweeping all tree branches in a backward manner (starting from the branch with the biggest index and heading towards the branch whose index equals 1), compute complex power at receiving end of branch via (2).

$$
\dot{S}_{i k}^{(r)}=\dot{S}_{k}^{(r)}+\sum_{m \in \Omega_{k}, m \neq i}\left[\dot{S}_{k m}^{(r)}+\left(\frac{S_{k m}^{(r)}}{U_{m}^{(r)}}\right)^{2} \dot{z}_{k m}\right] \quad k=N, N-1, \ldots, 2
$$

where $\Omega_{k}$ is the set of all buses connected to bus $k$ and $\dot{z}_{k m}$ is the series impedance of branch connected between node $k$ and node $m$.

Step 4 (Forward sweep):

Sweeping the tree in the opposite direction, update node voltages from the head by considering the respective branch voltage drops:

$$
\dot{U}_{k}^{(r+1)}=\dot{U}_{i}^{(r+1)}-\frac{\left(\dot{S}_{i k}^{(r)}\right)^{*}}{\left(\dot{U}_{k}^{(r)}\right)^{*}} \dot{z}_{i k} \quad k=2,3, \ldots, N
$$

Step 5:

Deploy (4) to compare voltages in iteration $(r+1)$ with the corresponding ones from iteration $r$. If the maximum difference in voltage magnitude and angle is less than the specified tolerance, the calculation process ends. Otherwise, go to Step 2.

$$
\max _{i=2,3, \ldots, N}\left\{\left|\dot{U}_{i}^{(r)}-\dot{U}_{i}^{(r+1)}\right|\right\} \leq \varepsilon
$$

\subsection{Modified DistFlow (MD) model}

\subsubsection{A two-bus system}

Consider a two-bus distribution network whose equivalent circuit diagram and vector diagram of the voltage drop are depicted in figure 1. The notation in this figure consists of:

- $P_{i j}$ and $Q_{i j}$ are the power flow at the sending bus $i$;

- $P_{j i}$ and $Q_{j i}$ are active power and reactive power flow at the receiving end $j$, respectively;

- $U_{i}$ and $U_{j}$ are the voltage magnitude at nodes $i$ and $j$, respectively;

- $\delta_{i j}$ is the phase angle difference between two adjacent buses $i$ and $j$;

- $R_{i j}$ and $X_{i j}$ are resistance and reactance of branch $i j$, respectively.

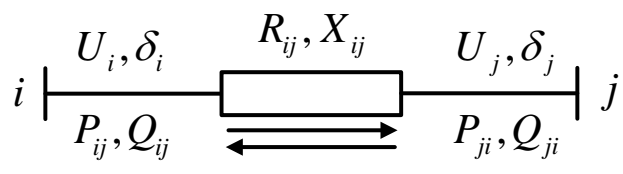

a)

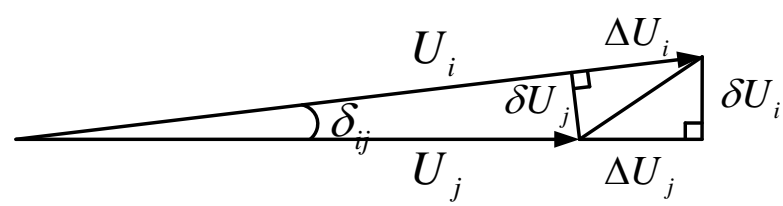

b)

Figure 1. Two-bus distribution system

a) Equivalent circuit diagram; b) Phasor diagram of the voltage drop

The respective expressions for calculating the horizontal and vertical direction components of the voltage drop are described below:

$$
\Delta U_{i}=\frac{R_{i j} P_{i j}+X_{i j} Q_{i j}}{U_{i}} ; \delta U_{i}=\frac{X_{i j} P_{i j}-R_{i j} Q_{i j}}{U_{i}}
$$


where bus $i$ is considered as the phase angle reference.

The Modified DistFlow method in this paper is developed using assumptions as follows [5].

The first assumption is that the difference between the phase angle at buses $i$ and $j$ can be neglected. With this assumption, the approximate formula as in (6) can be attained.

$$
\sin \delta_{i j} \approx \delta_{i j} ; \cos \delta_{i j} \approx 1-\frac{1}{2} \delta_{i j}^{2}
$$

From Figure 1, the horizontal direction element of the voltage drop can be computed via (7) as follows.

$$
\Delta U_{i}=U_{i}-U_{j} \cos \delta_{i j} \approx U_{i}-U_{j}\left(1-\frac{1}{2} \delta_{i j}^{2}\right) ; \Delta U_{j}=U_{i} \cos \delta_{i j}-U_{j} \approx U_{i}\left(1-\frac{1}{2} \delta_{i j}^{2}\right)-U_{j}
$$

To deploy the first assumption, an approximate equation is made as below.

$$
\Delta U_{i} \approx \Delta U_{j} ; \quad \delta U_{i}=U_{j} \delta_{i j} ; \quad \delta U_{j}=U_{i} \delta_{i j}
$$

By substituting (5) into (8) and leveraging the first assumption, the real and reactive power at the sending end is related to that of the receiving end as follows:

$$
\frac{P_{i j}}{U_{i}} \approx-\frac{P_{j i}}{U_{j}} ; \quad \frac{Q_{i j}}{U_{i}} \approx-\frac{Q_{j i}}{U_{j}}
$$

\subsubsection{Voltage expression of the two-bus distribution system}

The power flow of branch $i j$ at the sending end can be determined as follows:

$$
\begin{gathered}
P_{i j}=\frac{R_{i j}\left(U_{i}^{2}-U_{i} U_{j} \cos \delta_{i j}\right)+X_{i j} U_{i} U_{j} \sin \delta_{i j}}{R_{i j}^{2}+X_{i j}^{2}} \\
Q_{i j}=\frac{X_{i j}\left(U_{i}^{2}-U_{i} U_{j} \cos \delta_{i j}\right)-R_{i j} U_{i} U_{j} \sin \delta_{i j}}{R_{i j}^{2}+X_{i j}^{2}}
\end{gathered}
$$

To be multiplied (10) by $R_{i j}$ and (11) by $X_{i j}$ and by making use of the first assumption results to the following equation:

$$
U_{i}-U_{j} \approx R_{i j} \frac{P_{i j}}{U_{i}}+X_{i j} \frac{Q_{i j}}{U_{i}}
$$

Let

$$
\hat{P}_{i j}=\frac{P_{i j}}{U_{i}} ; \quad \hat{Q}_{i j}=\frac{Q_{i j}}{U_{i}} ; \quad \hat{P}_{i}=\frac{P_{i}}{U_{i}} ; \quad \hat{Q}_{i}=\frac{Q_{i}}{U_{i}}
$$

By employing the Taylor expansion, the following mathematical statement is obtained:

$$
U^{-1} \approx 2-U
$$

By combining equations (12)-(14), the voltage equation of the two-bus distribution is written as follows.

$$
U_{j}^{-1}-U_{i}^{-1}=R_{i j} \hat{P}_{i j}+X_{i j} \hat{Q}_{i j}
$$

The following expressions can be obtained using $W=U^{-1}$

$$
\hat{P}_{i}=P_{i} W_{i} ; \quad \hat{Q}_{i}=Q_{i} W_{i} ; \quad \hat{P}_{i j}=-\hat{P}_{j i} ; \quad \hat{Q}_{i j}=-\hat{Q}_{j i} ; \quad W_{j}-W_{i}=R_{i j} \hat{P}_{i j}+X_{i j} \hat{Q}_{i j} ;
$$

\subsubsection{The generalized form of Modified DistFlow}

The modified DistFlow model described in sections (2.2.1) and (2.2.2) is generalized using of following equations.

$$
\begin{gathered}
\hat{P}_{h i}=\sum_{j \in \Omega_{i}, j \neq h} \hat{P}_{i j}-\hat{P}_{i}, \quad \forall i \in N_{\mathrm{N}} ; \quad \hat{Q}_{h i}=\sum_{j \in \Omega_{i}, j \neq h} \hat{Q}_{i j}-\hat{Q}_{i}, \quad \forall i \in N_{\mathrm{N}} \\
W_{j}-W_{i}=R_{i j} \hat{P}_{i j}+X_{i j} \hat{Q}_{i j}, \quad \forall i j \in N_{\mathrm{B}} \\
\hat{P}_{i}=P_{i} W_{i} \quad \forall i \in N_{\mathrm{N}} ; \quad \hat{Q}_{i}=Q_{i} W_{i}, \quad \forall i \in N_{\mathrm{N}}
\end{gathered}
$$


where $N_{\mathrm{N}}$ is the set of buses of the power distribution system, $N_{\mathrm{B}}$ is the set of branches, and $\Omega_{i}$ is the set of buses connected directly to bus $i$.

Moreover, the model (17)-(19) can be described in a matrix form. The bus voltage can be computed as follows:

$$
\mathbf{U}_{\mathrm{R}}=\mathbf{2}-\left(\mathbf{I}+\mathbf{T}^{\mathrm{T}} \mathbf{R}_{\mathrm{N}} \mathbf{T} \mathbf{P}_{\mathrm{N}}+\mathbf{T}^{\mathrm{T}} \mathbf{X}_{\mathrm{N}} \mathbf{T} \mathbf{Q}_{\mathrm{N}}\right)^{-1}\left(\mathbf{2}-\mathbf{U}_{0}\right)
$$

The power flow of each branch can be achieved by applying the following forms:

$$
\begin{gathered}
\mathbf{P}_{\mathrm{Br}}=-\operatorname{diag}\left(\mathbf{2}-\mathbf{U}_{\mathrm{S}}\right)^{-1} \mathbf{T} \mathbf{P}_{\mathrm{N}}\left(\mathbf{2}-\mathbf{U}_{\mathrm{R}}\right) \\
\mathbf{Q}_{\mathrm{Br}}=-\operatorname{diag}\left(\mathbf{2}-\mathbf{U}_{\mathrm{S}}\right)^{-1} \mathbf{T} \mathbf{Q}_{\mathrm{N}}\left(\mathbf{2}-\mathbf{U}_{\mathrm{R}}\right)
\end{gathered}
$$

where:

- $\quad \mathbf{T}$ is the path-branch incidence matrix, in which the path of a node is a set of branches that link this node to the root node;

- $\quad \mathbf{R}_{\mathrm{N}}$ and $\mathbf{X}_{\mathrm{N}}$ are the diagonal matrix of $R_{i j}$ and $X_{i j}$, respectively;

- $\quad \mathbf{P}_{\mathrm{N}}$ and $\mathbf{Q}_{\mathrm{N}}$ are the diagonal matrix of real and reactive power injected to buses, respectively;

- $\mathbf{U}_{0}$ is the column vector in which values of the elements equal voltage magnitude of the reference bus;

- $\quad \mathbf{U}_{\mathrm{R}}$ is the vector of voltage magnitude at receiving ends;

- $\quad \mathbf{U}_{\mathrm{S}}$ is the vector of voltage magnitude at sending ends;

- $\quad \mathbf{P}_{\mathrm{Br}}$ and $\mathbf{Q}_{\mathrm{Br}}$ are the respective column vector of branch active and reactive power flow.

\subsection{Simplified DistFlow (SD) model}

Based on the assumption that the voltage magnitude at buses in power distribution systems is approximately equal to 1 under normal conditions, mathematical expressions (9) and (15) can be rewritten as follows [7]:

$$
P_{i j} \approx-P_{j i} ; \quad Q_{i j} \approx-Q_{j i} ; \quad U_{i}-U_{j}=R_{i j} P_{i j}+X_{i j} Q_{i j}
$$

Finally, the Simplified DistFlow model can be generally expressed as:

$$
\begin{gathered}
P_{h i}=\sum_{j \in \Omega_{i}, j \neq h} P_{i j}-P_{i}, \quad \forall i \in N_{\mathrm{N}} ; \quad Q_{h i}=\sum_{j \in \Omega_{i}, j \neq h} Q_{i j}-Q_{i}, \quad \forall i \in N_{\mathrm{N}} \\
U_{i}-U_{j}=R_{i j} P_{i j}+X_{i j} Q_{i j}, \quad \forall i j \in N_{\mathrm{B}}
\end{gathered}
$$

\subsection{Linearized Power Flow for Distribution (LPF-D)}

The linearized power flow model in this section is introduced in [8]-[9]. While Modified DistFlow and Simplified DistFlow models are branch power flow approaches, this section's linearized model is bus injection.

With the LPF-D model, the real and reactive power injected at bus $i$ are formed as follows.

$$
\begin{gathered}
P_{i}=\sum_{j=1, j \neq i}^{N} \frac{X_{i j}}{R_{i j}^{2}+X_{i j}^{2}}\left(\delta_{i}-\delta_{j}\right)+\frac{R_{i j}}{R_{i j}^{2}+X_{i j}^{2}}\left(U_{i}-U_{j}\right) \\
Q_{i}=\sum_{j=1, j \neq i}^{N}-\frac{R_{i j}}{R_{i j}^{2}+X_{i j}^{2}}\left(\delta_{i}-\delta_{j}\right)+\frac{X_{i j}}{R_{i j}^{2}+X_{i j}^{2}}\left(U_{i}-U_{j}\right)
\end{gathered}
$$

\subsection{Discussion about the relation between Simplified DistFlow and LPF-D model}

With the approach of Linearized Power Flow for Distribution represented in Section 2.4, the real and reactive power flow of branch $i j$ at bus $i$ can be computed as follows: 


$$
\begin{gathered}
P_{i j}=\frac{X_{i j}}{R_{i j}^{2}+X_{i j}^{2}}\left(\delta_{i}-\delta_{j}\right)+\frac{R_{i j}}{R_{i j}^{2}+X_{i j}^{2}}\left(U_{i}-U_{j}\right) \\
Q_{i j}=-\frac{R_{i j}}{R_{i j}^{2}+X_{i j}^{2}}\left(\delta_{i}-\delta_{j}\right)+\frac{X_{i j}}{R_{i j}^{2}+X_{i j}^{2}}\left(U_{i}-U_{j}\right)
\end{gathered}
$$

By respectively multiplying equations (28) and (29) by $R_{i j}$ and $X_{i j}$ :

$$
\begin{gathered}
R_{i j} P_{i j}=\frac{R_{i j} X_{i j}}{R_{i j}^{2}+X_{i j}^{2}}\left(\delta_{i}-\delta_{j}\right)+\frac{R_{i j}^{2}}{R_{i j}^{2}+X_{i j}^{2}}\left(U_{i}-U_{j}\right) \\
X_{i j} Q_{i j}=-\frac{R_{i j} X_{i j}}{R_{i j}^{2}+X_{i j}^{2}}\left(\delta_{i}-\delta_{j}\right)+\frac{X_{i j}^{2}}{R_{i j}^{2}+X_{i j}^{2}}\left(U_{i}-U_{j}\right)
\end{gathered}
$$

From expressions (30) and (31), the following equation is attained:

$$
R_{i j} P_{i j}+X_{i j} Q_{i j}=U_{i}-U_{j}
$$

The mathematical statement (32) is entirely the same as the voltage equation (23).

Furthermore, the power flows of branch $i j$ at bus $j$ is expressed below:

$$
\begin{gathered}
P_{j i}=\frac{X_{i j}}{R_{i j}^{2}+X_{i j}^{2}}\left(\delta_{j}-\delta_{i}\right)+\frac{R_{i j}}{R_{i j}^{2}+X_{i j}^{2}}\left(U_{j}-U_{i}\right)=-P_{i j} \\
Q_{j i}=-\frac{R_{i j}}{R_{i j}^{2}+X_{i j}^{2}}\left(\delta_{j}-\delta_{i}\right)+\frac{X_{i j}}{R_{i j}^{2}+X_{i j}^{2}}\left(U_{j}-U_{i}\right)=-Q_{i j}
\end{gathered}
$$

The equations (33) and (34) show that the line losses are ignored when applying the LPF-D model. These equations are precisely the same as the expression (23). Therefore, the Simplified DistFlow and LPF-D models are identical.

\section{Results and discussion}

In this section, the voltage magnitudes and branch power flows using different linear methods are calculated on a six-bus distribution system depicted in Figure 2. The nominal voltage of this system equals $10 \mathrm{kV}$.

The resistance and reactance of all line branches are identical and equal to $0.33 \Omega / \mathrm{km}$ and $0.395 \Omega / \mathrm{km}$, respectively. Moreover, the voltage magnitude of the power supply point is set as 1.05 p.u. The complex power of demand at each bus in this test system is given as follows $\left(S_{\mathrm{cb}}=1000 \mathrm{kVA}\right)$ :

$$
\begin{aligned}
& \dot{S}_{2}=1.4+j 0.7 ; \dot{S}_{3}=1.2+j 0.45 ; \\
& \dot{S}_{4}=0.8+j 0.5 ; \dot{S}_{5}=1+j 0.6 ; \dot{S}_{6}=2.5+j 1.2
\end{aligned}
$$

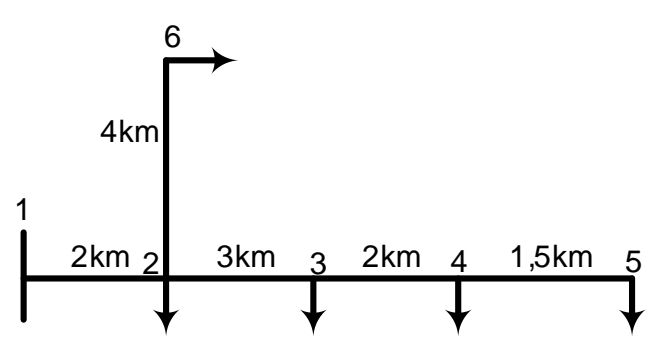

Figure 2. Six-bus distribution system

\subsection{Results from Modified DistFlow (MD) Model}

By using the equations demonstrated in Section 2.2, matrixes are built as follows:

$$
\mathbf{P}_{\mathrm{N}}=\left[\begin{array}{ccccc}
-1.4 & 0 & 0 & 0 & 0 \\
0 & -1.2 & 0 & 0 & 0 \\
0 & 0 & -0.8 & 0 & 0 \\
0 & 0 & 0 & -1 & 0 \\
0 & 0 & 0 & 0 & -2.5
\end{array}\right] ; \quad \mathbf{Q}_{\mathrm{N}}=\left[\begin{array}{ccccc}
-0.7 & 0 & 0 & 0 & 0 \\
0 & -0.45 & 0 & 0 & 0 \\
0 & 0 & -0.5 & 0 & 0 \\
0 & 0 & 0 & -0.6 & 0 \\
0 & 0 & 0 & 0 & -1.2
\end{array}\right]
$$


Respective matrix of $\mathbf{R}_{\mathrm{N}}$ and $\mathbf{X}_{\mathrm{N}}$ :

$\left[\begin{array}{ccccc}0.0066 & 0 & 0 & 0 & 0 \\ 0 & 0.0099 & 0 & 0 & 0 \\ 0 & 0 & 0.0066 & 0 & 0 \\ 0 & 0 & 0 & 0.00495 & 0 \\ 0 & 0 & 0 & 0 & 0.0132\end{array}\right] ;\left[\begin{array}{ccccc}0.0079 & 0 & 0 & 0 & 0 \\ 0 & 0.01185 & 0 & 0 & 0 \\ 0 & 0 & 0.0079 & 0 & 0 \\ 0 & 0 & 0 & 0.005925 & 0 \\ 0 & 0 & 0 & 0 & 0.0158\end{array}\right]$

Voltage magnitude of buses, active and reactive power flow of line branches at sending end:

$$
\mathbf{U}_{\mathrm{R}}=\left[\begin{array}{l}
U_{2} \\
U_{3} \\
U_{4} \\
U_{5} \\
U_{6}
\end{array}\right]=\left[\begin{array}{l}
0.9714 \\
0.9185 \\
0.8957 \\
0.8862 \\
0.9150
\end{array}\right] ; \quad \mathbf{P}_{\mathrm{Br}}=\left[\begin{array}{l}
P_{12} \\
P_{23} \\
P_{34} \\
P_{45} \\
P_{26}
\end{array}\right]=\left[\begin{array}{l}
7.8394 \\
3.2033 \\
1.8467 \\
1.0086 \\
2.6370
\end{array}\right] ; \quad \mathbf{Q}_{\mathrm{Br}}=\left[\begin{array}{l}
Q_{12} \\
Q_{23} \\
Q_{34} \\
Q_{45} \\
Q_{26}
\end{array}\right]=\left[\begin{array}{l}
3.9253 \\
1.6596 \\
1.1285 \\
1.2658 \\
2.6370
\end{array}\right]
$$

\subsection{Errors of linear models}

In this study, calculated results using the Power Summation Method are performed by MATPOWER software [11] and are considered as the benchmark. The computed results of voltage magnitudes, real and reactive power flows from the PSM, and the errors of models, including MD, SD and LPF-D, are revealed in Figure 3 to Figure 5, respectively.

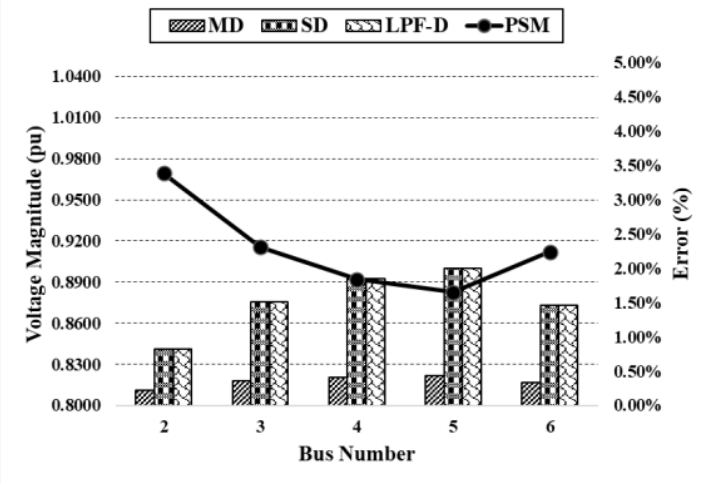

Figure 3. Results of voltage magnitude

It can be observed from these figures that the results from MD are closest to that of PSM. While the maximum voltage error of MD is $0.43 \%$, the figures for SD and LPF-D are the same and equal to $2.00 \%$. Similarly, the largest errors for active power flow and reactive power flow using $\mathrm{MD}$ are $2.13 \%$ and $10.35 \%$, respectively. At the same time, the branch active and reactive power flow errors of SD and LPF-D are identical and several times higher than that of MD, at $10.10 \%$ and $21.20 \%$, respectively.

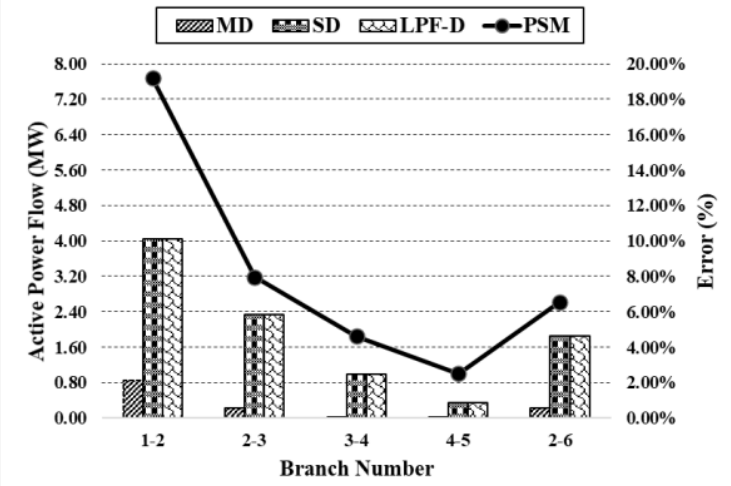

Figure 4. Results of active power flow

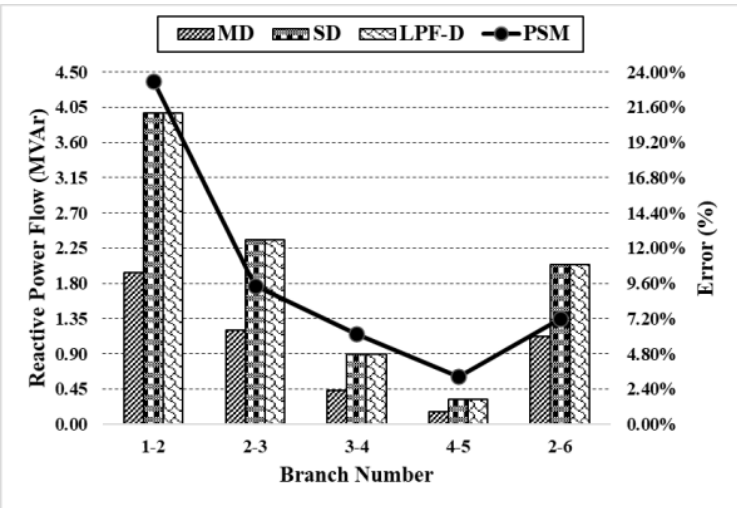

Figure 5. Results of reactive power flow 


\section{Conclusion}

This paper studies various methodologies, including the Alternating Current Power Flow (ACPF) model like Power Summation Method (PSM) and linear power flow forms, such as Simplified DistFlow (SD), Modified DistFlow (MD) and Linearized Power Flow for Distribution (LPF-D), to calculate voltage magnitude, branch active power flow and branch reactive power flow in steady-state distribution grids. The results reveal that the solution obtained with MD is more accurate than that of SD and LPF-D and is closer to the solution achieved with PSM. In addition, the authors have proved that mathematical equations and calculated results of SD and LPF-D are identical. These findings provide valuable information for the Distribution System Operator (DSO) to effectively manage, operate and plan distribution systems.

\section{REFERENCES}

[1] P. N. Van, "Power flow incorporating cost-based droop control strategies for ac autonomous microgrids," J. Sci. Technol. Issue Inf. Commun. Technol., vol. 18, no. 12.1, pp. 28-32, 2020, doi: 10.31130/jst-ud2020-124e.

[2] D. Rajičić, R. Ačkovski, and R. Taleski, "Voltage correction power flow," IEEE Trans. Power Deliv., vol. 9, no. 2, pp. 1056-1062, 1994, doi: 10.1109/61.296308.

[3] M. E. Baran and F. F. Wu, "Optimal sizing of capacitors placed on a radial distribution system," IEEE Trans. Power Deliv., vol. 4, no. 1, pp. 735-743, 1989.

[4] Z. Tian, W. Wu, B. Zhang, and A. Bose, "Mixed-integer second-order cone programming model for VAR optimization and network reconfiguration in active distribution networks," IET Gener. Transm. Distrib., vol. 10, no. 8, pp. 1938-1946, 2016, doi: 10.1049/iet-gtd.2015.1228.

[5] T. Yang, Y. Guo, L. Deng, H. Sun, and W. Wu, "A Linear Branch Flow Model for Radial Distribution Networks and Its Application to Reactive Power Optimization and Network Reconfiguration," IEEE Trans. Smart Grid, vol. 12, no. 3, pp. 2027-2036, 2021, doi: 10.1109/TSG.2020.3039984.

[6] P. N. Van, "A comparative study of PTDF based-methods to determine transmission usage allocation for bilateral transactions in power markets," TNU J. Sci. Technol., vol. 226, no. 06, pp. 82-89, 2021.

[7] L. Bai, J. Wang, C. Wang, C. Chen, and F. Li, "Distribution Locational Marginal Pricing (DLMP) for Congestion Management and Voltage Support," IEEE Trans. Power Syst., vol. 33, no. 4, pp. 40614073, 2018, doi: 10.1109/TPWRS.2017.2767632.

[8] H. Yuan, F. Li, Y. Wei, and J. Zhu, "Novel linearized power flow and linearized OPF models for active distribution networks with application in distribution LMP," IEEE Trans. Smart Grid, vol. 9, no. 1, pp. 438-448, 2018, doi: 10.1109/TSG.2016.2594814.

[9] J. Yang, N. Zhang, C. Kang, and Q. Xia, "A state-independent Linear Power Flow Model with Accurate Estimation of Voltage Magnitude," IEEE Trans. Power Syst., vol. 32, no. 5, pp. 3607-3617, 2017, doi: 10.1109/TPWRS.2016.2638923.

[10]T. Yang, Y. Guo, L. Deng, H. Shu, X. Shen, and H. Sun, "A distribution system loss allocation approach based on a modified distflow model," IEEE Power Energy Soc. Gen. Meet., August 2020, doi: 10.1109/PESGM41954.2020.9281770.

[11]R. D. Zimmerman, C. E. Murillo-Sánchez, and R. J. Thomas, "MATPOWER: Steady-state operations, planning, and analysis tools for power systems research and education," IEEE Trans. Power Syst., vol. 26, no. 1, pp. 12-19, 2011, doi: 10.1109/TPWRS.2010.2051168. 